\title{
CODE MIXING DALAM PENGGUNAAN BAHASA INDONESIA PADA MASYARAKAT DAYAK BIDAYUH DI GUN TEMBAWANG (PERBATASAN INDONESIA-MALAYSIA)
}

\author{
Lilian Slow $^{1}$ dan Puji Rahmawati ${ }^{2}$ \\ ${ }^{1,2}$ Dosen STKIP Melawi (Kampus Entikong) \\ Jln. Kuari Yayasan Lintas Batas Kecamatan Entikong Kabupaten Sanggau \\ lilianslow87@gmail.com, puji_rahmawati89@yahoo.com
}

\begin{abstract}
Code mixing is the mixing process between two or more languages in an utterance or a sentence in language phenomena. The phenomena tends to happen to the speakers who speak more than one language in the social interaction. Indonesia has many and hundred ethnic languages and dialect diversities. Moreover, for the people who live in the nation border area is easy to get the possibility to be influenced of the other languages or dialects in that community. One of the border areas in West Kalimantan that directly next to Malaysia border area is Gun Tembawang village, in Entikong sub-district, Sanggau district. The speech community in Gun Tembawang is indicated to use more languages. They usual mix the language using Malay dialect of Malaysia when they speak Bahasa. Some words of the malay dialects are, for instances, cakap (talk/speak), beng (bank), tengok (see), and tengah hari (noon). Therefore, this research conducts to find out the kinds of code mixing that appear in the Gun Temawang people when they speak Bahasa. Method of this research used qualitative descriptive method. It is a survey research used the data collecting by interview technique toward Gun Tembawang people, directly. The data of this research is their utterance in Bahasa. The result of this research shows that the kind of code mixing that appears in Gun Temawang people's utterance is insertion. It is a process when the speaker mix by insert one word, words or phrase in a sentence.
\end{abstract}

Keywords: code mixing, insertion, alternation, congruent lexicalization, and gun temawang.

\begin{abstract}
Abstrak: Code mixing merupakan peristiwa pencampuran dari beberapa bahasa yang digunakan dalam satu ujaran atau satu kalimat. Peristiwa ini cenderung terjadi dalam tuturan masyarakat yang menggunakan lebih dari satu bahasa dalam interaksi sosialnya. Negara Indonesia menjadi salah satu negara dengan ratusan bahasa daerah dan keberagaman dialek. Terlebih lagi pada masyarakat yang berada di daerah peratasan negara yang memungkinkan pengaruh penggunaan bahasa dari negara tetangga tersebut. Salah satu wilayah perbatasan di Kalimantan Barat, di Indonesia yang langsung berbatasan dengan wilayah negara Malaysia, yaitu Dusun Gun Tembawang, Kecamatan Entikong, Kabupaten Sangggau. Masyarakat tutur di Gun Tembawang terindikasi selalu mencampur bahasa Malaysia ketika mereka berbicara bahasa indonesia. Beberapa kosakata dari bahasa melayu Malaysia seperti cakap (bicara), beng (bank), tengok (lihat), dan tengah hari (siang).Oleh karena itu, penelitian ini dilakukan dengan tujuan untuk
\end{abstract}


mengetahui jenis-jenis campur kode apa saja yang muncul dalam tuturan mereka ketika berbahasa indonesia. Metode yang digunakan adalah metode kualitatif deskriptif. Penelitian ini merupakan penelitian survei dengan teknik pengamilan data menggunakan wawancara terhadap masyarakat Gun Tembawang. Data yang dianalisis adalah tuturan mereka ketika proses wawancara berlangsung dengan menggunakan bahasa indonesia. Hasil penelitian ini menunjukkan bahwa jenis campur kode yang muncul dalam tuturan masyarakat Gun Tembawang berjenis insertion, yaitujenis campur kode yang menyisipkan kata atau frasa dalam satu kalimat.

Kata kunci: campur kode, penyisipan, alternasi, leksikal kongruen, dan gun tembawang.

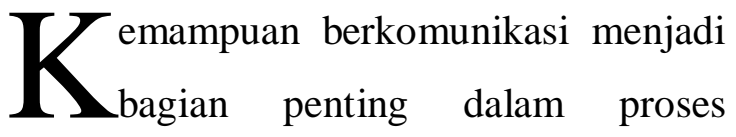

interaksi di masyarakat. Interaksi sosial akan berjalan dengan baik apabila penutur dapat saling menyampaikan dan memaknai pesan dengan baik. Hal tersebut dapat terwujud apabila penutur dan lawan bicaranya dapat menggunakan bahasa yang dimengerti oleh kedua belah pihak. Kemampuan berkomunikasi juga sangat dipengaruhi oleh kemampuan yang dimiliki oleh penuturnya. Kemampuan tersebut juga sangat dipengaruhi oleh

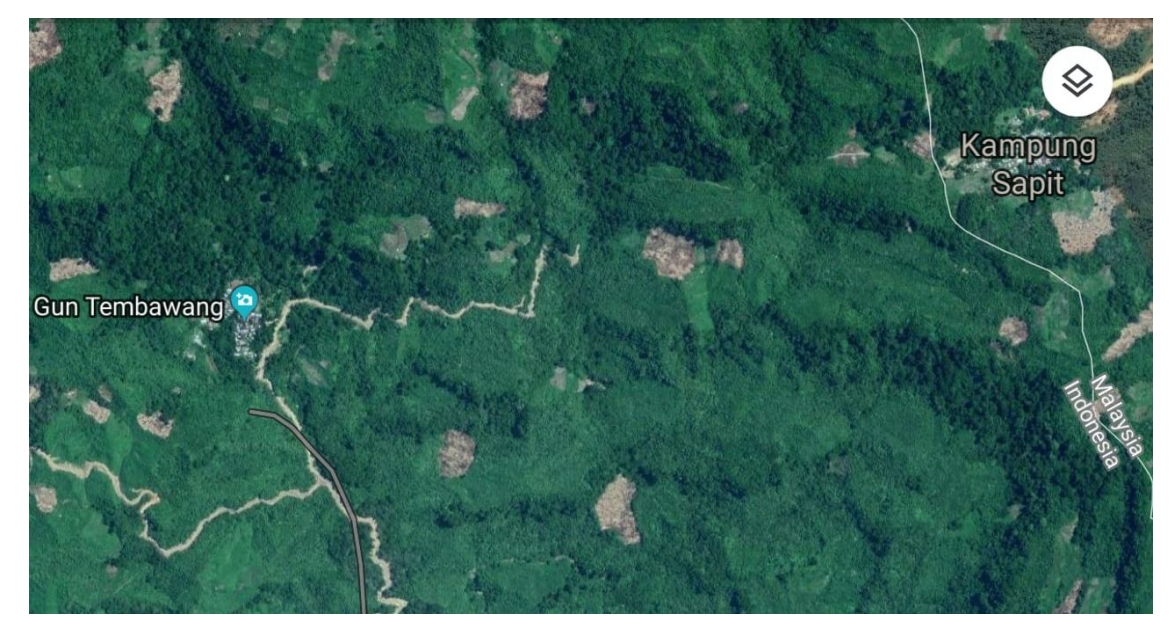

Gambar 1. Dusun Gun Tembawang (Indonesia) dan Kampung Sapit (Malaysia)

Gun Tembawang merupakan sebuah dusun yang jauh dipelosok Kalimantan faktor-faktor dari luar atau masyarakat. Salah satu faktor luar yang dapat mempengaruhi kemampuan tersebut adalah tingkat interaksi dalam berkomunikasi. Kurangnya interaksi dalam berkomunikasi pastinya akan mempengaruhi kebiasaan penutur dalam mengasah kemampuannya. Keterbatasan interaksi dalam bermasyarakat pastinya menjadi permasalahan tersendiri bagi masyarakat yang berada di daerah terpencil atau terisolasi.

tersebut juga sangat dipengaruhi oleh

46| J P D, p- I S S N : 2252-8156, e - I S S N : $2579-3993$ 
tetangga, yaitu Malaysia. Hal tersebut pastinya memberikan pengaruh yang besar dalam banyak aspek. Satu diantaranya adalah aspek komunikasi masyarakat Gun Temawang. Adanya keberagaman suku, bahasa dan budaya di daerah tersebut membentuk masyarakat yang multilingual. Kondisi masyarakat tutur yang multilingual ini memungkinkan terjadinya banyak peristiwa dalam bahasa, salah satunya adalah peristiwa campur kode (code mixing).Campur kode dapat diartikan sebagai peristiwa yang mencampurkan beberapa kata dari unsur bahasa lain dalam sebuah ujaran.

Campur kode terjadi apabila seorang penutur menggunakan suatu bahasa secara dominan mendukung suatu tuturan disisipi dengan unsur bahasa lainnya. Hal ini biasanya berhubungan dengan karakteristik penutur, seperti latar belakang sosial, tingkat pendidikan, rasa keagamaan (Thamimi dkk., 2015: 4).Campur kode dapat dimaknai sebagai percampuran bahasa. Menurut Muysken (2000: 1) code mixing is refer to all cases where lexical items and gramatical features from two languages appear in one sentence. Pendapatlain yang dinyatakan oleh Sumarsih dkk. ( 2014: 79) bahwa code mixing is a mixture between two or more languages in which there is a dominant language and inserted with different language to make it sound cool and give appropriate context to the audience or listener.

Sejalan dengan pendapat Siregar (2016) bahwa code mixing is the use of one language in another language, the mixing of two or more languages or language varieties in a speech. Code mixing often happens when the use of two languages or two cultures can not be separated from the elements of one language well and often overlap between the two sytems are in use. Selain itu, Chaer dan Agustina (2010: 114) menambahkan bahwa dalam campur kode ada sebuah kode utama atau kode dasar yang digunakan dan memiliki fungsi dan keotonomiannya, sedangkan kode-kode lain yang terlibat dalam peristiwa tutur itu hanyalah berupa serpihan-serpihan (piece) saja, tanpa fungsi atau keotonomian seagai sebuah kode.

Berdasarkan beberapa pendapat mengenai campur kode tersebut dapat disimpulkan bahwa campur kode merupakan percampuran yang terdiri dari dua atau lebih bahasa yang berbeda dalam satu ujaran atau satu kalimat. percampuran tersebut dapat muncul dalam bentuk leksikal per kata atau frasa bahkan klausa dan ragam bahasa lain dalam satu kalimat. penelitian ini akan menganalisis campur kode yang dilakukan oleh masyarakat Gun Tembawang dalam berkomunikasi menggunakan Bahasa Indonesia. 


\section{METODE PENELITIAN}

Penelitian ini merupakan penelitian survei dan metode yang digunakan adalah metode deskriptif kualitatif menggunakan pendekatan sosioliguistik tentang campur kode. Penelitian survei adalah penelitian yang mengambil sampel dari satu populasi dan menggunakan kuesioner sebagai alat pengumpulan data yang pokok (Singarimbun, 1995:3). Selain itu, menurut M. Nazir (2011: 56)pengertian penelitian survei adalah penyelidikan yang dilakukan untuk mendapatkan fakta-fakta dari gejala yang ada dan mencari keteranganketerangan secara faktual baik tentang institusi sosial, ekonomi atau politik dari suatu kelompok atau suatu individu.

Sedangkan metode deskriptif menurut Nawawi (dalam Darmadi, 2014: 185) merupakan prosedur pemecahan masalah yang diselidiki dengan menggambarkan/melukiskan keadaan subjek/objek penelitian (seseorang, lembaga, masyarakat, dan lain-lain) pada saat sekarang berdasarkan fakta-fakta yang tampak, atau sebagaimana adanya. Sedangkan menurut Ratna (2016: 94) penelitian kualitatif tidak semata-mata mendeskripsikannya, tetapi yang lebih penting adalah menemukan makna yang terkandung dibaliknya, sebagai makna tersembunyi, atau dengan sengaja disembunyikan, seperti mengapa kesadaran itu kurang, cukup, dan sebagainya. Pendeskripsian data dalam penelitian ini adalah data kualitatif dari hasil rekaman wawancara.Tahap awal yang dilakukan dalam penelitian ini adalah menyiapkan skrip wawancara, melakukan rekaman wawancara secara langsung pada responden, menganalisa data dengan kajian sosiolinguistik dengan teori campur kode. Data yang dianalisis adalah data kualitatif.Tahap terakhir adalah menyimpulkan hasil analisis data.

\section{Lokasi Penelitian}

Lokasi penelitian adalah dusun Gun Tembawang, desa Suruh Tembawang, kecamatan Entikong, Kalimantan Barat.

\section{Peubah yang Diamati/Diukur}

Penelitian ini akan mengamati kemampuan berkomunikasi dengan menganalisis tuturan masyarakat Gun Tembawang. 


\section{Rancangan Penelitian}

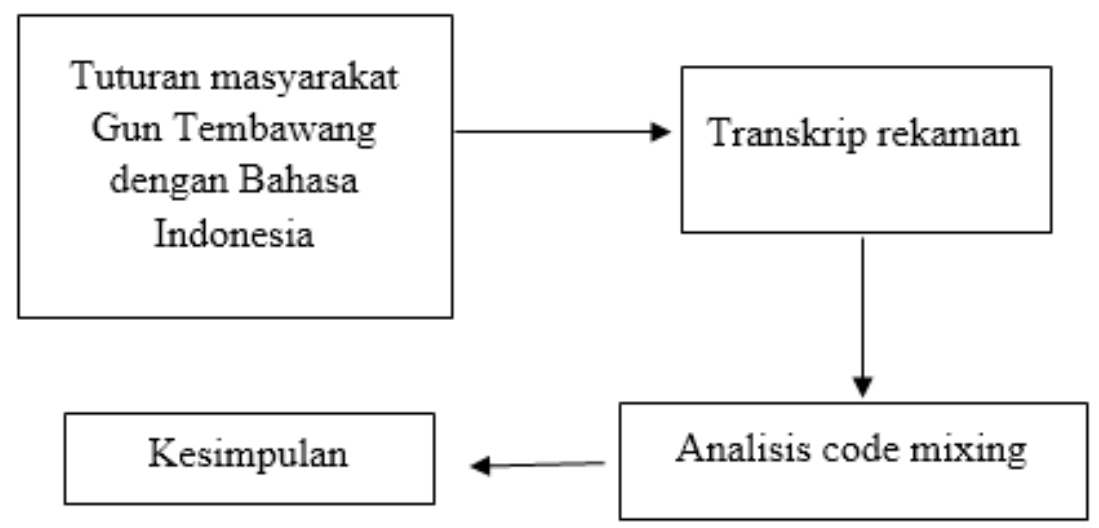

Gambar 1. Rancangan Penelitian

\section{Teknik Pengumpulan Data dan Analisis}

\section{Data}

Data akan dikumpulkan dengan teknik wawancara langsung ke masyarakat Gun Tembawang. Data dianalisis dengan teknik deskriptif pada data kualitatif dalam kajian campur kode. Data kualitatif berupa tuturan dari hasil wawancara dalam penggunaan bahasa Indonesia oleh responden dan akan dianalisis campur kode yang dilakukan. Langkah-langkah analisis data dalam penelitian ini tergambar berdasarkan Sugiono (2013: 52) adalah tahap pengumpulan data. Tahap pengumpulan data akan dilakukan secara langsung dengan mewawancarai responden satu per satu. Pengumpulan data dilakukan dengan merekam percakapan selama proses wawancara berlangsung. Kemudian tahap reduksi. Proses yang dilakukan pada tahap reduksi adalah mentranskrip hasil rekaman wawancara terlebih dahulu kemudian data transkrip akan diidentifikasi berdasarkan jenis alih kode. Tahap berikutnya, yaitu tahap penyajian data. Tahap penyajian data dilakukan dengan menganalisis teori campur kode. Terakhir adalah tahap penarikan kesimpulan mengenai analisis campur kode yang terjadi.

\section{HASIL PENELITIAN}

Campur kode (Code Mixing)

Campur kode merupakan peristiwa yang lazim terjadi pada masyarakat bilingual maupun multilungual. Campur kode dalam proses berkomunikasi akan menimbulkan interferensi dalam pengkajian bahasa. Berdasarkan data interferensi pada tuturan masyarakat Gun Tembawang mengindikasikan adanya proses campur kode dalam tuturan mereka. Pencampuran kode yang dilakukan oleh masyarakat Gun Tembawang dalam berkomunikasi dengan Bahasa Indonesia 
dinilai mengacaukan struktur dan kaidah

Bahasa Indonesia yang seharusnya digunakan. Oleh karena itu, campur kode yang terjadi akan diklasifikasikan ke dalam beberapa jenis, yaitu insertion, alternation, dan congruent lexicalization
(Muysken, 2000: 3). Berikut ini beberapa contoh code mixing berdasarkan data wawancara langsung. Contoh kalimat hanya ditampilkan satu contoh saja untuk tiap jenis code mixing.

Tabel 1. Jenis Code Mixing

\begin{tabular}{|c|c|c|}
\hline No. & Kalimat & Jenis code mixing \\
\hline 1. & Memang saya lancar ngomong cakap malaysia tu. & Insertion \\
\hline 2. & Ada ..ada yang campur, ada yang engak. & Insertion \\
\hline 3. & Bahasa kampung bisa, pakai bahasa indonesia saya endak bisa. & Insertion \\
\hline 4. & Susah nak ngomong. & Insertion \\
\hline 5. & $\begin{array}{l}\text { Kalau kitak ketemu dengan orang lain kitak tanya pakai Bahasa } \\
\text { Indonesia. }\end{array}$ & Insertion \\
\hline 6. & Tak pandai bahasa indonesia. & Insertion \\
\hline 7. & $\begin{array}{l}\text { Bahasa kampung jak, ada bahasa kampong...ada...kalau ada } \\
\text { yang orang biasa yang pakai bahasa ya pakai bahasa dia. }\end{array}$ & Insertion \\
\hline 8. & Biasa, bukan susah. & Insertion \\
\hline 9. & $\begin{array}{l}\text { Ada juga lah waktu saya sekolah di kampung cuman waktu } \\
\text { saya sekolah tu... }\end{array}$ & Insertion \\
\hline 10. & Suka sih kalau masuk ke situ aja bisa pakai itu aja... & Insertion \\
\hline 11. & Selamat tengah hari. & - \\
\hline 12. & Tidak susah kita bahasa indonesia...paling senang. & Insertion \\
\hline 13. & Guna...bahasa indonesia. & Insertion \\
\hline 14. & Sebab itu guna di jarannya... di bandar-bandarnya. & Insertion \\
\hline 15. & $\begin{array}{l}\text { Memang dirasa pentinglah bahasa indonesia, penting untuk } \\
\text { kita warga negara Indonesia. }\end{array}$ & Insertion \\
\hline 16. & $\begin{array}{l}\text { Memang...kurang tentu...kadang-kadang sejak saya berumur } \\
\text { belasan tahunlah. }\end{array}$ & Insertion \\
\hline 17. & $\begin{array}{l}\text { karena saya pengen bahasa indonesia nanti saya takut poris } \\
\text { (polis) jumpa...polisi, tentara, bupati kah, presiden kah. }\end{array}$ & Insertion \\
\hline
\end{tabular}

\footnotetext{
Berdasarkan data di atas menunjukkan bahwa code mixing yang muncul terdiri dari satu jenis code mixing, yaitu insertion saja. Campur kode jenis insertion berkaitan dengan penyisipan kata atau frasa dengan kata lain penyisipan dilakukan terhadap unsur sintaksis, yang
} dapat berbentuk unsur leksikal atau frasa (Ramadhani, 2011). Sebagaimana penjelasan Muysken (2000: 3):

Insertion of material (lexical items or entire constituents) from one language into a structure of the other language. Insertion is the constraint in the terms of structural 
properties of some base or matrix structure. The process of code mixing is conceived as something skin to borrowing and insertion of an alien lexical or phrasal category into a given structure. The difference is simply the size and type of element inserted - noun, adjective, verb, and the like.

Kata cakap, nak, tak, bukan susah, tengah hari, paling senang, guna, bandarbandarnya, dirasa, kurang tentu, dan poris (polis) merupakan kosakata dari bahasa melayu negara Malaysia yang disisipkan oleh penutur ketika berbahasa Indonesia. Kata cakap yang berarti bicara, nak yang berarti ingin/mau, tak yang berarti tidak, bukan susah yang berartimudah, tengah hari yang berarti siang, paling senang yang berarti paling mudah/sangat mudah, guna yang berarti menggunakan/untuk, bandar yang berarti kota, dirasa yang berarti dianggap, kurang tentu yang berarti tidak jelas/tidak pasti, dan poris (polis) yang berarti polisi (KBBI, 2016). Kata bandarbandarnya juga merupakan reduplication insertion atau penyisipan pengulangan kata (Suwito, 1985: 78). Kata (11) selamat tengah hari pada data tersebut merupakan proses alih kode (code switching) sehingga tidak termasuk dalam kategori code mixing.

Selain itu, campur kode insertion pada kata enggak, endak, dan aja merupakan kata-kata yang berasal dari kosakata tidak baku yang berkembang di pulau jawa pada umumnya. Kemudian, campur kode insertion pada kata kitak (kamu/kalian), cuman(Cuma), dan jak(saja)merupakan sisipan yang berasal dari dialek melayu di daerah kecamatan Entikong.

Data pada tabel 1 tidak terdapat jenis code mixing alternation dan congruent lexicalization. Sebagaimana penjelasan Muysken bahwa alternation is the constraint of mixing in terms of compatibility or equivalence of the languages involved at the mix point, and clause. Dengan kata lain, tidak terdapat peristiwa campur kode yang menunjukkan percampuran dalam klausa dan dalam proses ini dua bahasa ditampilkan dalam satu klausa namun tetap relatif terpisah sehingga memungkinkan terjadinya peminjaman leksikal dalam proses tersebut. Selain itu, hal yang mengindikasi tidak adanya jenis alternation ini adalah tidak terdapat rangkaian yang dialihkan diawali dan diikuti oleh elemen bahasa lain, dan elemen-elemen tersebut tidak terhubung secara struktural (Ramadhani, 2011).

Begitu juga dengan congruent lexicalization. Muysen berpendapat bahwa Congruent lexicalization of material from different lexical inventories into a shared grammatical structure. It is also the influence of dialect within language use. Dapat disimpulkan bahwa congruent lexicalization berkaitan dengan dialek dari 
ragam bahasa tertentu. Ramadhani menyimpulkan bahwa dalam proses pencampuran ini terdapat kesejajaran linier dan struktural pada tataran sintaksis dan ragam bahasa. Struktur pencampuran ini cenderung non-nested a b a namun terhubung secara struktural. Berdasarkan penjelasan mengenai alternation dan congruent lexicalization di atas maka data code mixing dari tuturan masyarakat Gun Tembawang tidak menunjukkan adanya proses pencampuran kode dalam kedua jenis pencampuran tersebut.

\section{SIMPULAN}

Campur kode yang terjadi dalam tuturan masyarakat Gun Temawang adalah campur kode dengan jenis insertion. Terdapat tujuh belas kosakata yang merupakan campur kode dalam penggunaan Bahasa Indonesia, yaitu cakap, enggak, endak, nak, tak, bukan susah, paling senang, tengah hari, guna, dirasa, kurang tentu, bandar-bandarnya, dan poris (polis). Hal ini menunjukkan bahwa dalam penuturan Bahasa Indonesia pada masyarakat Gun Temawang mendapat banyak campuran dari dialek bahasa Melayu, baik dari dialek melayu Entikong (Sanggau) dan dialek Melayu Malaysia. selain itu, campuran kode juga menggunakan kosakata tidak baku yang berkembang dan lazim digunakan di daerah pulau Jawa.

\section{DAFTAR PUSTAKA}

Chaer dan Agustina. 2010. Sosiolinguistik: Perkenalan Awal. Jakarta: Rineka Cipta.

Darmadi, H. 2014. Metode Penelitian Pendidikan dan Sosial. Bandung. Alfabeta.

KBBI. 2016. Kamus Besar Bahasa Indonesia (KBBI) (Online), edisi V, (http://kbbi.web.id, diakses 7 oktober 2019).

Muysken, P. 2000. Bilingual Speech: A Typology of Code-Mixing. Cambridge: Cambridge University Press.

Nazir, M. 2011. Metode Penelitian. Bogor: Ghalia Indonesia.

Ramadhani, A. 2011. Campur Kode Bahasa Indonesia-Bahasa Inggris dalam Acara "Welcome to BCA" di Metro TV. Tesis Program Studi Linguistik. Depok. Fakultas Ilmu Pengetahuan Budaya, Universitas Indonesia.

Ratna, 2010. Metodologi Penelitian, kajian Budaya dan Ilmu Sosial Humaniora pada Umumnya. Yogyakarta: Pustaka Pelajar.

Siregar, Nuraida dkk. 2016. A Descriptive Analysis of Code Mixing in Facebook Social Networking at Eighth Semester Students of English Study Program in University of Pasir pengaraian. Skripsi. Pasir Pangairan: Universitas Pasir Pangairan. 
Jurnal Pendidikan Dasar, 7 (2), Desember 2019

Singarimbun, M. 1995. Metode Penelitian

Survei. Semarang: IKIP Semarang Press.

Sugiono. 2013. Metode Penelitian Kuantitatif Kualitatif dan $R \& D$. Bandung: Alfabeta.

Sumarsih, dkk. 2014. "Code Switching and Code Mixing in Indonesia: Study in
Sociolinguistics". Jurnal: English Language and Literature Studies, Vol.(4), 1. Published by Canadian Center of Science and Education. Suwito. 1985. Alih Kode, Campur Kode, Interferensi. Surakarta: Binary Offset. 